\title{
Health Belief Model and PRECEDE PROCEED on the Risk Factors of Multidrug Resistant Tuberculosis in Surakarta, Central Java
}

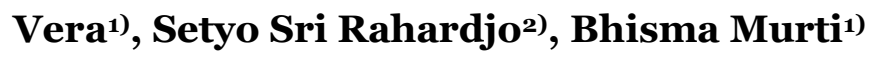 \\ 1) Masters Program in Public Health, Sebelas Maret University \\ 2) Faculty of Medicine, Sebelas Maret University
}

\begin{abstract}
Background: Tuberculosis (TB) is one of the lethal infectious diseases in the world. One of the current biggest challenges of Tuberculosis control is the widespread emergence of Multidrug Resistant Tuberculosis (MDR-TB). There are several potential risk factors of MDR-TB that can be explained by Health Belief Model and PRECEDE PROCEED model framework. This study aimed to analyzed factors associated with MDR-TB using Health Belief Model and PRECEDE PROCEED.

Subjects and Method: This was an analytic observational study with case control design. The study was conducted at Dr. Moewardi Hospital and BBKPM, Surakarta, from September to November 2017. The study subjects were selected using fixed disease sampling, consisting of 76 MDR-TB patients and 228 TB patients. The dependent variable was MDR-TB. The independent variables were educational level, self-efficacy, drug-taking adherence, smoking, nutritional status, perceived of susceptibility, perceived barrier, perceived severity, perceived benefit, and drug-taking supervisor. The data were collected using questionnaire and analyzed by path analysis.

Results: The risk of MDR-TB was increased by lack of drug-taking adherence $(b=-1.69 ; 95 \% \mathrm{CI}=-$ 2.28 to $-1.09 ; \mathrm{p}<0.001)$, poor nutritional status $(\mathrm{b}=1.32 ; 95 \% \mathrm{CI}=0.72$ to $1.92 ; \mathrm{p}<0.001)$, and smoking $(b=1.32 ; 95 \% \mathrm{CI}=0.72$ to $1.92 ; \mathrm{p}<0.001)$. Drug-taking adherence was increased by perceived susceptibility $(b=0.91 ; 95 \% C I=0.18$ to $1.63 ; p=0.015)$, perceived severity $(b=1.01 ; 95 \%$ $\mathrm{CI}=0.28$ to $1.74 ; \mathrm{p}=0.007)$, perceived benefit $(\mathrm{b}=1.69 ; 95 \% \mathrm{CI}=0.97$ to $2.41 ; \mathrm{p}<0.001)$, drugtaking advisor $(b=2.16 ; 95 \% \mathrm{CI}=1.44$ to $2.88 ; \mathrm{p}<0.001)$, self efficacy $(\mathrm{b}=1.58 ; 95 \% \mathrm{CI}=0.86$ to 2.31; $\mathrm{p}<0.001)$, and low perceived barrier $(\mathrm{b}=-1.10 ; 95 \% \mathrm{CI}=-1.82$ to $-0.38 ; \mathrm{p}=0.003)$.
\end{abstract}

Conclusion: The risk of MDR-TB is increased by the lack of drug-taking adherence, poor nutritional status, and smoking.

Keyword: Health belief model, PRECEDE-PROCEED, MDR-TB

\section{Correspondence:}

Vera. Masters Program in Public Health, Sebelas Maret University, Jl. Ir. Sutami 36 A, Surakarta 57126, Central Java. Email: vera21210@gmail.com

\section{BACKGROUND}

Tuberculosis (TB) is one of the lethal infectious diseases in the world (WHO, 2016a). Indonesia ranks second among countries with the highest TB cases in the world with $10 \%$ of the global number (WHO, 2016b). Tuberculosis treatment and control is getting more difficult because of the increasing cases of resistant TB bacteria (Hoza, Mfinanga and König, 2015). MDR TB turns to be a new challenge in TB control program since the diagnosis establishment is difficult and the mortality rate and failure rate are high (WHO, 2015). In Indonesia there are 17 provinces with $\mathrm{TB}$ treatment success rate $<85 \%$, one of them is Central Java Province. TB cases in Surakarta was the third highest in Central Java Province's Case Notification Rate (CNR) in 2016 with a total of 85 per 100,000 population (Kementerian Kesehatan RI, 2016).

Ding et al. (2017) explains that insufficient knowledge and perception is one of the factors that increasing the incidence of MDR TB. Zhang et al. (2016) 
reveals that inappropriate or inadequate treatment becomes the main determinant of MDR TB incidence. It is associated with patients' adherence in the medication process. The adherence is affected by various sides whether it is from within themselves or healthcare providers. Skrahina et al. (2013) mentioned that there are other factors that may affect MDR TB namely alcohol consumption and smoking. In addition according to Patiung et al. (2014) one of the factors related to the TB patients is nutritional status. One of the models recommended to explain and understand health behavior including TB patients' drug taking adherence is Health Belief Model (HBM) (Tola et al., 2016). In addition to HBM, PRECEDE PROCEED model is also good to be used in understanding health behavior.

The purpose of the study was to analyze factors associated with MDR TB by using Health Belief Model and PRECEDE PROCEED model.

\section{SUBJECTS AND METHOD}

\section{Study design}

It was analytic observational study with case control design. The study was conducted in Dr. Moewardi Hospital and BBKPM (Community Lung Health Center) Surakarta in November 2017.

\section{Population and sample}

The case population was patients of MDRTB in Dr. Moewardi hospital. Meanwhile the control population was tuberculosis patients in BBKPM Surakarta and Dr. Moewardi Hospital.

The sampling technique used was fixed disease sampling. There were a total of 304 study subjects, the number of case sample was 76 patients of MDR TB dan the number of control sample was 228 patients of tuberculosis. Inclusion criteria were study subjects $\geq 15$ years of age and able to answer questionnaires well. The exclusion criteria was patient with mental disorder.

\section{Study variables}

The dependent variable was MDR TB. The independent variables included drug-taking adherence, smoking, nutritional status, perceived susceptibility, perceived severity, perceived benefit, perceived barrier, support from drug taking advisor, educational level and alcohol consumption.

\section{Operational definition of variables}

Drug-taking adherence was defined as patients' compliance to take anti TB drug regularly and completely. The data were collected by questionnaires. The measurement scale was categorical, coded o for no and 1 for yes.

Perceived susceptibility was defined as negative or positive perception toward individual's risk of contracting MDR TB. The data were collected by questionnaires. The measurement scale was continuous, but for the purpose of data analysis, the scale was transformed into dichotomous, coded o for low perceived susceptibility and 1 for high perceived susceptibility.

Perceived severity was defined as an individual subjective perception toward the severity of the consequence of MDR TB. The data were collected by questionnaires. The measurement scale was continuous, but for the purpose of data analysis, the scale was transformed into dichotomous, coded $\mathrm{o}$ for low perceived severity and 1 for high perceived severity.

Perceived benefit was defined as patients' belief toward the advantages of the treatment to reduce the risk of MDR TB. The data were collected by questionnaires. The measurement scale was continuous, but for the purpose of data analysis, the scale was transformed into dichotomous, coded $\mathrm{o}$ for low perceived benefit and 1 for perceived benefit. 
Perceived barrier was defined as patients' belief toward the obstacles to undergone the treatment thus may result in the risk for MDR TB incidences. The data were collected by questionnaires. The measurement scale was continuous, but for the purpose of data analysis, the scale was transformed into dichotomous, coded o for low perceived barrier and 1 for perceived barrier.

Support from drug-taking advisor was defined as someone who ensures regularity or TB drug-taking adherence during patients' TB treatment period of time. The data were collected by questionnaires. The measurement scale was continuous, but for the purpose of data analysis, the scale was transformed into dichotomous, coded o for weak support and 1 for strong support.

Self efficacy was defined as a belief within oneself to conduct a behavior of drug-taking adherence in reducing the risk of MDR TB incidences. The data were collected by questionnaires. The measurement scale was continuous, but for the purpose of data analysis, the scale was transformed into dichotomous, coded o for low self-efficacy and 1 for high self-efficacy.

Nutritional status was defined as assessment on patients' nutritional states based on anthropometric assessment covering body weight and height and it was measured by body scale and microtoise stature meter. The nutritional status was measured by body mass index (BMI) calculated from body weight (kgBW) / body height $\left(\mathrm{m}^{2}\right)$, transformed into dichotomous scale, coded o if $18.5 \leq \mathrm{BMI}<25.0$ (normoweight) and 1 if $\mathrm{BMI}<18.5$ (underweight) or $\geq 25$. 0 (overweight or obese).

Educational level was defined as the last formal education attained to get a certificate. The data were collected by questionnaires. The measurement scale was categorical, but for the purpose of analysis transformed into dichotomous, coded o for $<$ Senior high school and 1 for $\geq$ Senior high school.

Alcohol consumption was defined as a behavior to consume drinks that contained ethyl alcohol or ethanol whether it was in the past of present days. The data were collected by questionnaires. The measurement scale was categorical, coded o for not drinking alcohol and 1 for drinking alcohol.

Smoking was defined as a behavior of actively smoking cigarette whether it was in the past or present days. The data were collected by questionnaires. The measurement scale was categorical, coded o for not smoking and 1 for smoking.

MDR TB was defined as resistant to the two first line medications rifampisin and isoniazid with or without the resistance to other TB medications. The data was measured by Xpert MTB/RIF.

\section{Data analysis}

The sample characteristics were described in frequency and percent, for categorical data. The bivariate analysis involving categorical data was run by cross tabulation with odds ratio as the measure of the association and Chi square as the statistical test. Multivariate analysis used path analysis to determine the direct and indirect effects of the relationships between study variables. Path analysis steps included model specification, model identification, model fit, parameter estimate, and model re-specification.

\section{Research Ethics}

The research ethical clearance was granted from the Research Ethics Committee at Dr. Moewardi Hospital, Surakarta, Central Java, Indonesia. Research ethics included issues such as informed consent, anonymity, confidentiality, and ethical clearance. 


\section{RESULTS}

\section{Sample characteristics Subjects}

Sample characteristics were depicted in Table 1. The proportion of study subjects aged below or above 40 years is about equal. By sex distribution, male subjects slightly out-numbered female subjects. By employment status, about three quarters of the study subjects were employed. About a third of the study subjects earned income $\geq$ $\mathrm{Rp}$ 2,100,000. Most of the study subjects were married. About $10 \%$ of the study subjects had contact with a tuberculosis case. Most of the study subjects had no comorbidity.

Table 1. Sample distribution by age, sex, employment, income, marital status, tuberculosis contact, and comorbidities, for case group and control group.

\begin{tabular}{|c|c|c|c|c|c|}
\hline \multirow{2}{*}{ No } & \multirow{2}{*}{ Characteristics } & \multicolumn{2}{|c|}{ Case } & \multicolumn{2}{|c|}{ Control } \\
\hline & & $\mathbf{N}$ & $\%$ & $\mathbf{N}$ & $\%$ \\
\hline \multirow[t]{3}{*}{1.} & Age (years) & & & & \\
\hline & $<41$ & 34 & 44.7 & 111 & 48.7 \\
\hline & $\geq 41$ & 42 & $55 \cdot 3$ & 117 & 51.3 \\
\hline \multirow[t]{3}{*}{2.} & Sex Categories & & & & \\
\hline & Male & 50 & 65.8 & 122 & $53 \cdot 3$ \\
\hline & Female & 26 & 34.2 & 106 & 46.5 \\
\hline \multirow[t]{3}{*}{3.} & Employment & & & & \\
\hline & Unemployed & 13 & 17.1 & 54 & 23.7 \\
\hline & Employed & 63 & 82.9 & 174 & 76.3 \\
\hline \multirow[t]{3}{*}{4.} & Income (Rupiah) & & & & \\
\hline & Insufficient $(<\mathrm{Rp} 2,100,000)$ & 56 & 73.7 & 152 & 66.7 \\
\hline & Sufficient ( $\geq$ Rp 2,100,00o) & 20 & 26.3 & 76 & 33.3 \\
\hline \multirow[t]{3}{*}{5 . } & Marital Status & & & & \\
\hline & Not Married & 11 & 14.5 & 40 & $17 \cdot 5$ \\
\hline & Married & 65 & 85.5 & 188 & 82.5 \\
\hline \multirow[t]{3}{*}{6.} & Tuberculosis Contact & & & & \\
\hline & No Contact & 58 & 76.3 & 205 & 89.9 \\
\hline & Contact & 18 & 23.7 & 23 & 10.1 \\
\hline \multirow[t]{3}{*}{7.} & Comorbidities & & & & \\
\hline & No & 56 & 73.7 & 211 & 92.5 \\
\hline & Yes & 20 & 26.3 & 17 & 7.5 \\
\hline
\end{tabular}

\section{Path Analysis}

Multivariate analysis of the data employed path analysis model that was run on STATA 13 program. The path analysis proceeded in five steps:
a. model specification,
b. model identification,
c. model fit,
d. parameter estimate, and
e. model re-specification

\section{Model specification}

Figure 1 depicts the path model specification that followed the conceptual framework.

\section{Model identification}

The number of observed variables was 12, endogenous variables were 4 and exogenous variables were 8 , the number of degree of freedom (df) value was 54 . Since the $\mathrm{df}=$ $54 \geq 0$, it indicates that the sample size was sufficient to run a path analysis model. 


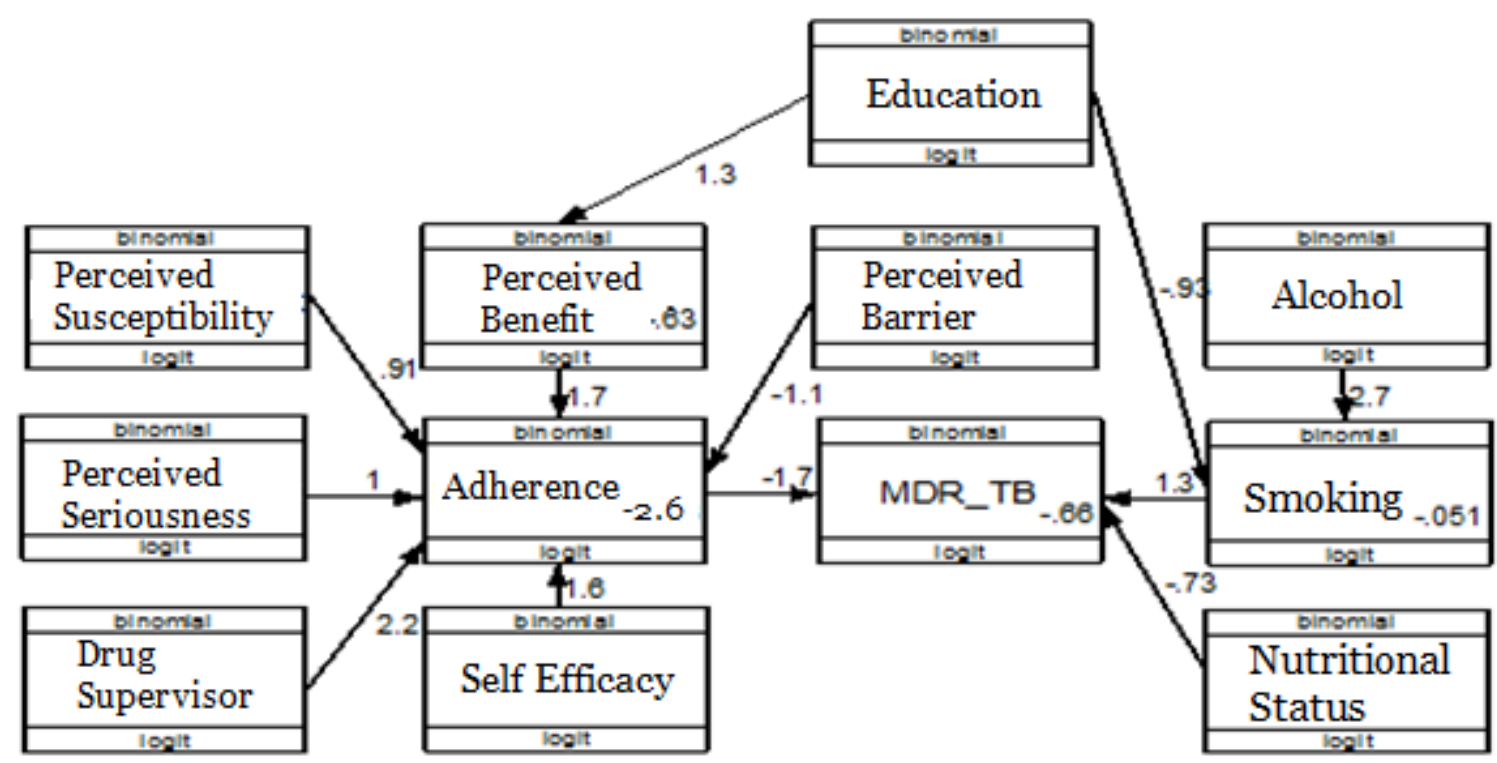

Figure 1. Path Analysis on Risk Factors of Multidrug Resistant Tuberculosis

Table 2. The result of path analysis on risk factors of multidrug resistant tuberculosis

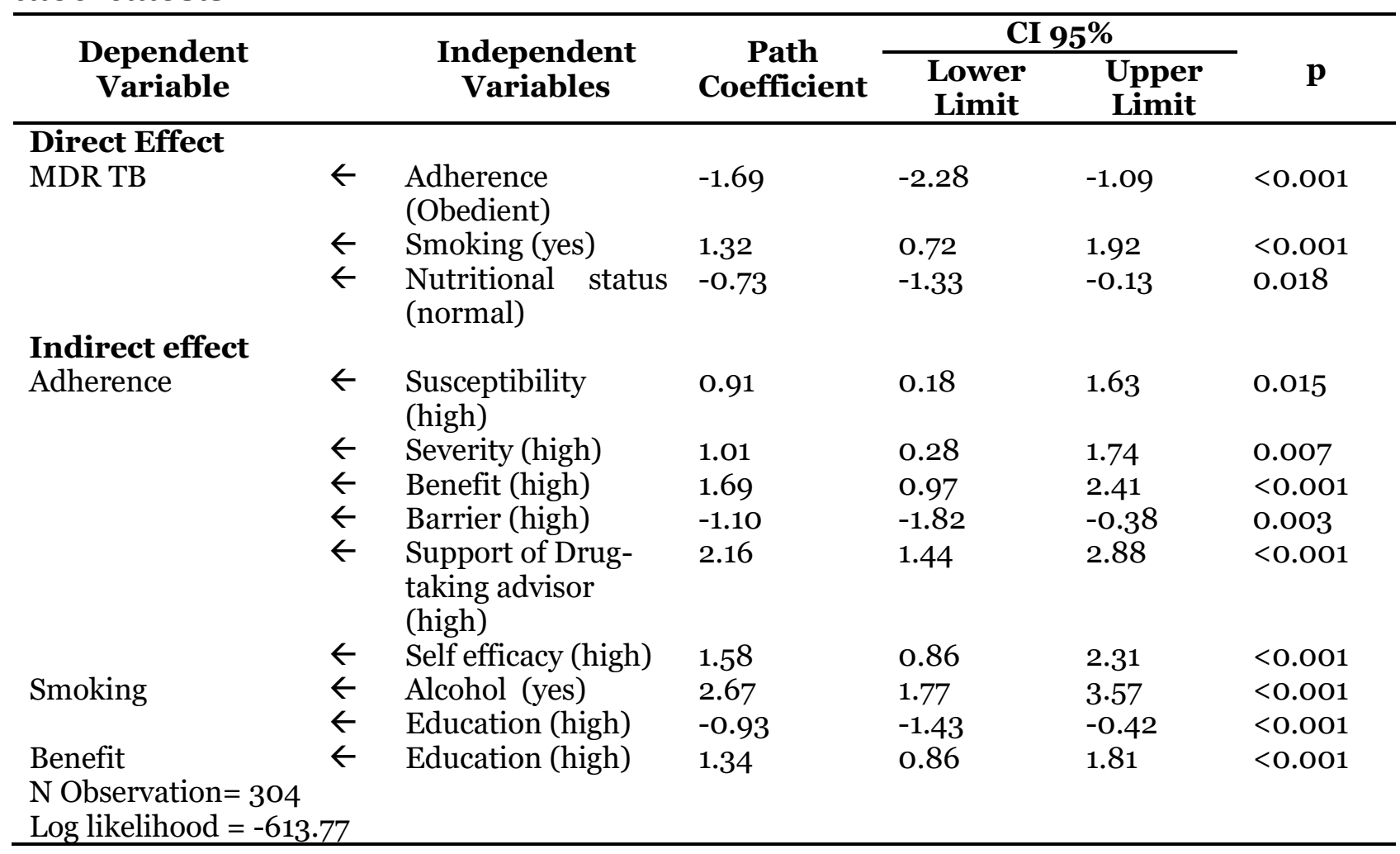

There was an association between adherence and MDR TB and it was significant. People who were obedient were less likely to endure MDR TB ( $b=-1.69$; CI $95 \%=-2.28$ up to $-1.09 ; \mathrm{p}<0.001)$. There was an association between smoking and MDR TB and it was significant. People who used to smoke were likely to endure MDR TB $(b=1.32$; CI $95 \%=0.72$ to $1.92 ; \mathrm{p}$ $<0.001)$. There was an association between 
Journal of Epidemiology and Public Health (2017), 2(3): 241-254

https://doi.org/10.26911/jepublichealth.2017.02.03.06

nutritional status and MDR TB and it was significant. People with sufficient nutritional status were less likely to endure MDR TB $(\mathrm{b}=-0.13$; CI $95 \%=-1.33$ to $-0.13 ; \mathrm{p}=$ 0.018). There was an association between perceived susceptibility and drug taking adherence and it was significant. People with high perceived susceptibility were more likely to be obedient $(\mathrm{b}=0.91$; $\mathrm{CI}$ $95 \%=0.18$ to $1.63 ; \mathrm{p}=0.015$ ). There was an association between perceived severity and drug-taking adherence and it was significant. People with high perceived severity were more likely to be obedient $(\mathrm{b}=$ 1.01; CI $95 \%=0.28$ up to $1.74 ; \mathrm{p}=0.007$ ).

There was an association between perceived benefit and drug taking adherence and it was significant. People with high perceived benefit were more likely to be obedient $(b=1.69$; CI $95 \%=0.97$ to $2.41 ; \mathrm{p}<0.001)$. There was an association between perceived barrier and drug taking adherence and it was significant. People with high perceived barrier were less likely to be obedient ( $b=1.10$; CI $95 \%=-1.82$ to $0.38 ; \mathrm{p}=0.003$ ). There was an association between support from drug taking advisor and drug taking adherence and it was significant. People with high support from drug taking advisor were more likely to be obedient $(\mathrm{b}=2.16$; $\mathrm{CI} 95 \%=2.16$ to 2.88 ; $\mathrm{p}<$ o.001). There was an association between self efficacy and drug taking adherence and it was significant. People with high self efficacy were more likely to be obedient $(b=$ 1.58; CI $95 \%=0.86$ to $2.31 ; \mathrm{p}<0.001)$. There was an association between alcohol consumption and smoking and it was significant. People who had ever consume alcohol were more likely to smoke $(b=2.67$; CI $95 \%=1.77$ to $3.57 ; \mathrm{p}<0.001)$. There was an association between educational and smoking. People with high educational level were less likely to smoke $(b=-0.93$; CI $95 \%=-1.43$ hingga $-0.42 ; \mathrm{p}<0.001)$. There was an association between educational level and perceived benefit and it was significant. People with high educational level were more likely to have high perceived benefit $(b=1.34$; CI 95\% $=0.86$ hingga 1.81; $\mathrm{p}<0.001$ ).

\section{DISCUSSION \\ 1. The association between drug taking adherence and MDR TB}

WHO (2014) reveals that if TB patients are not obedient in taking anti TB medications, thus the failure of TB healing will be the final result to worry about, furthermore the emergence of TB bacillus which is resistant to TB medications. The result of analysis of the study showed that there was direct association between patients' adherence in taking TB medications with MDR TB incidences that was negative in nature and significant. It was supported by a study of Hirpa et al. (2013) which mentioned that the most dominant factor and might directly influence MDR TB was TB patients' disobedience to the treatment.

Zhdanov et al., (2017) stated that medication disobedience which often occur in the first two months active phase caused by patients have feel better and stop the treatment. It may trigger the recurrence and resistance to TB medications. Khan et al., (2017) and Patel et al. (2017) mentioned TB patients who are obedient to the treatment are reported to have lower risk of MDR TB. It is generated by complete and as recommended treatment therefore there is no recurring tuberculosis that may generate the occurrence of sensitivity to medications.

\section{The association between smoking and MDR TB}

The result of the study showed that there was a direct association between smoking and MDR incidences that was positive and significant. The result of the study was in accordance with the previous study that 
stated there were an effect of smoking habit at the present days as well as smoking history toward the occurring MDR condition (Molalign and Wencheko, 2015). It is found that smoking reduces body immune. Not only it worsens the TB condition to become resistant to medications, it also leads to the risk of recurrence when TB has been treated (Mollel and Chilongola, 2017). As the result of severity level on smoking group, it may generate the increasing risk of resistance to medications therefore it increase mortality rate. Furthermore, the result of the study showed that almost one fifth burden caused by tuberculosis disease may be prevented by eliminating smoking behavior (Bonacciet al., 2013). Belchior et al., (2016) added that smoking may worsen the manifestation of TB disease.

\section{The Association between Nutri- tional Status and MDR TB}

Nutrition is needed in the process of repairing tissues and preventing disease. The association between TB and malnutrition has been indentified for long. Malnutrition reduce body immune, therefore it increase the possibility for medications resistant TB (WHO, 2013). The analysis result showed there was a direct association between nutritional status and MDR TB incidences that was negative and significant. It is supported by a study by Hicks et al. (2014) which revealed one one the factors influence MDR TB incidences and even continued to death namely poor nutritional status on TB patients. Putri et al. (2014) mentioned that poor nutritional status caused treatment of the patients became less effective and prevent the occurrence of sputum culture conversion in the initial phase of MDR TB treatment. It is elaborated by Park et al. (2016) and Tang et al. (2013) that poor nutritional status is often discovered on patients who endure resistance to TB medication because of the decreasing body immune that disturb immune system toward mycobacteruim tuberculosis. Imunitas tubuh pasien yang tidak baik akan berpengaruh pada semakin parahnya penyakit atau menjadi resisten terhadap obat tuberkulosis(Sun et al., 2017).

\section{The association between perceived susceptibility and MDR TB through drug taking adherence}

Rosenstock et al., (1988) stated that HBM is one of the oldest model that discuss the preparation to conduct health behavior based on several individual beliefs and perception. The result of analysis showed that there was an indirect association between perceived susceptibility with MDR TB incidences through variable of patients' adherence in taking TB medications. Direct association between perceived susceptibility and drug taking adherence was positive and significant. The study result was in accordance with the previous finding that mentioned individual belief role in HBM influenced individual decision in increasing health behaviors, one of them was adherence in taking TB medications (Johari et al., 2014; Tola et al., 2016).

\section{The association between severity perception and MDR TB through drug taking adherence}

HBM elaborates perceived severity within an individual and may influence individual in taking action (Simpson, 2015). The result of analysis showed that there was an indirect association between perceived severity and MDR TB incidences through TB drug taking adherence. Direct association between perceived severity and drug taking adherence was positive and significant. Individual action to conduct treatment and prevention for a disease will be encouraged by the severity of the disease. The bigger the risk of the disease the more likely the individual feel threatened. The 
Journal of Epidemiology and Public Health (2017), 2(3): 241-254

https://doi.org/10.26911/jepublichealth.2017.02.03.06

threat encourages individual action to conduct prevention and treatment for the disease (Tang et al., 2015; Woimo et al., 2017).

\section{The association between perceived benefit with MDR TB through drug taking adherence}

In accordance with HBM model an individual has a perception on the benefit to be experienced if conducting behavior change (Burke, 2015). The result of analysis showed that there was an indirect association between perceived benefit and MDT TB incidences through variable of patients' TB drug taking adherence. Direct association between perceived benefit and drug taking adherence was positive and significant. It is in accordance with a study by Horne et al.(2013) which mentioned that patients who believe that the undergone treatment will give positive impact for themselves will be more obedient toward the treatment. In addition, someone with high perception toward the benefit of tuberculosis treatment will reduce any obstacles or barriers they experience. Based on a study by Viegas et al. (2014), perceived benefit may get improved by making excellent communication between health personnel and TB patients. It is expected that with good communication, health personnel may give the appropriate education about the benefits and importance of regular treatment.

\section{The Association between Perceived Barrier and MDR TB through Drug Taking Adherence}

Based on HBM concept individuals have perception concerning the experienced barriers that it may influence individuals to not change their behavior (Burke, 2015). The result of analysis showed that there was indirect association between perceived barrier and MDR TB through variable of patients' TB drug taking adherence. Direct association between perceived barrier and drug taking adherence was negative and significant. It I supported by a study by Baral et al. (2014); Boru et al. (2017); Herrero et al. (2015) which elaborated that barriers may reduce adherence in undergoing TB treatment. In broad line the barriers are financial and social barrier. Further, when patient's belief toward barriers or obstacles is reduced or disappears then the adherence will be increasing. It is proven by the improvement on treatment regularity when $\mathrm{TB}$ treatment is given for free. Treatment regularity is believed and expected to reduce the incidences of resistance to $\mathrm{TB}$ medications (Eastment et al., 2017; Tupasi et al., 2017; Zhang et al., 2015). Shringarpure et al. (2016) mentioned that geographic location also influence patients' adherence in $\mathrm{TB}$ treatment. The road condition makes it difficult to go to healthcare facilities or because the distance is too far makes TB patients are reluctant to have medical examination in reliable health care facilities.

\section{The association between support from drug-taking advisors and MDR TB through drug-taking adherence.}

Cues to Action is a part of HBM which is anything that encourage decision in changing behavior (Hoorn et al., 2016). The result of the test showed that there was an indirect association between the support from drug-taking advisor and MDR TB incidences through variable of patients' $\mathrm{TB}$ drug-taking adherence. Direct association between support from drug-taking advisor and drug-taking adherence was positive and significant. It is in accordance with the result of previous study which stated that there was a significant association between support from drug-taking advisors during treatment and drug-taking adherence. It 
was elaborated by Craig and Zumla (2015) and Deshmukh et al. (2015) that after in depth interview with the patients they found a phenomenon that patients who were not supported or encouraged by their family to take TB medications were likely to be in despair in undergoing their treatment.

Good knowledge concerning tuberculosis disease needs to be accompanied by the support from closest people or drugtaking advisor. Tuberculosis patients who live alone and far from their family or neighbors will be more likely to stop tuberculosis treatment before its time. (Ali and Prins, 2016; Khanal et al., 2017).

\section{The association of self efficacy and MDR TB through drug-taking adherence}

Self-efficacy is one of the components of HBM. If individuals do not believe or confident that they can carry out behavior change, then they cannot do it (Simpson, 2015). The result of analysis showed that there was an indirect association between MDR TB incidences through variable of patients' TB drug-taking adherence. Direct association between self efficacy and drugtaking adherence was positive and significant. It is supported by the previous study that stated low self efficacy will give impact to treatment disobedience (DiefenbachElstob et al., 2017; Muhammed et al., 2015). Also added by Sanchez-Padilla et al. (2014) that patients' knowledge concerning to TB treatment needs to be supported by TB patients' belief of being able or capable to undergo TB treatment obediently so that it will not drop out. Self Efficacy can be established from the surrounding environment.

\section{The association of alcohol con- sumption and MDR TB through smoking}

Habit of consuming alcohol can give impact to one's habit or behavior that tend to smoke (Pedro et al., 2017). Result of the study showed that there was an indirect association between alcohol consumption and MDR TB incidences through variable of smoking. Direct association between alcohol consumption and smoking was positive and significant. It is in accordance with the result of previous study which stated that alcohol consumption is one of the predispositions of smoking behavior (Kuchukhidze et al., 2014; Zhang et al., 2017). Based on the findings by Skrahina et al. (2013) alcohol abuse and alcohol use disorder is identified to contribute in TB development and also the result of $\mathrm{TB}$ treatment. However, association between alcohol and MDR TB is possibly not direct causal association. Gaete and Araya (2017) and Jawad et al., (2014) discovered study result that one who smokes, after being traced, is a former alcohol drinker or even is still an alcohol drinker. Alcohol consumption and smoking behavior are adjacent phenomena.

\section{The association between educa- tional and MDR TB through Smoking}

The result of analysis showed that there was an indirect association between educational level and MDR TB incidences through smoking. Direct association between educational level and smoking was negative and significant. It is in accordance with a study conducted before, that educational level had big influence toward smoking behavior. With good educational level it is expected that people will have the awareness toward the danger of smoking for themselves and other people (Silva et al., 2017). Those who have low educational level are more likely to be smokers. It is because one with higher educational level will accept and comprehend information about the danger of smoking more easily. (Yaya et al., 2017). From a study by Pärna 
et al. (2014) it is discovered that smoking activity among men and women with high educational level is likely to be decreasing significantly.

\section{The association between educa- tional level and MDR TB through perceived benefit and drug-taking adherence}

The result of analysis showed that there was an indirect association between educational level and MDR TB through variable of perceived benefit and drug-taking adherence. Direct association between educational level and perceptions was positive and significant. It is in accordance with the result of previous study that mentioned that there was an association between educational level and perceived benefit in which it influenced adherence toward treatments (Fagundez et al., 2016).

High educational level improve patients' awareness and perception toward the big benefit of the importance of appropriate tuberculosis treatment (ChungDelgado et al., 2015). Perception on the benefit is influenced by TB patients' characteristics; one of them is educational level. In which perceived benefit itself in the end will influence treatment adherence that ends with TB drug resistance (Ma et al., 2015) dan (Ndwiga, Kikuvi and Omolo, 2016).

Based on the result of path analysis it can be concluded that MDR TB risk is decreasing along with the improvement of drug-taking adherence, nutritional status. MDR TB risk is increasing with the increasing of smoking. MDR TB risk is decreasing with the improvement of perceived susceptibility, perceived severity, perceived benefit, support from drug-taking advisor, and self efficacy through drug taking adherence. MDR TB risk is increasing along with the increasing of perceived barrier, through drug-taking adherence. MDR TB risk is increasing along with the increasing of alcohol consumption through smoking. MDR TB risk is decreasing along with the improving educational level through smoking. MDR TB risk is decreasing along with the improving educational level through perceived benefit and drug taking adherence.

\section{REFERENCES}

Ali AOA, Prins MH (2016). Patient Non Adherence to Tuberculosis Treatment in Sudan: Socio Demographic Factors Influencing Non Adherence to Tuberculosis Therapy in Khartoum State. Pan African Medical Journal, 25(80): 1-11.

Baral SC, Aryal Y, Bhattrai R, King R, Newell JN (2014). The Importance of Providing Counselling and Financial Support to Patients Receiving Treatment for Multi-Drug Resistant TB: Mixed Method Qualitative and Pilot Intervention Studies.BMC Public Health, 14(46): 1-7.

Belchior ADS, Mainbourg EMT, FerreiraGoncalves MJ. (2016). Loss to FollowUp in Tuberculosis Treatment and Its Relationship with Patients' Knowledge of The Disease and Other Associated Factors.Revista de Salud Publica (Bogota, Colombia), 18(5): 714726.

Bonaccia RA, Cruz-Hervert LP, GarcíaGarcía L, Reynales-Shigematsua LM, Ferreyra-Reyes L, Bobadilla-del-Valle M, Canizales-Quintero S et al. (2013). Impact of Cigarette Smoking on Rates and Clinical Prognosi of Pulmonary Tuberculosis in Southern Mexico. Journal of Infection, 66(4): 303-312.

Boru C, Shimels T, Bilal AI (2016). Factors Contributing to Non-Adherence with Treatment Among TB Patients in 
Sodo Woreda, Gurage Zone, Southern Ethiopia: A qualitative Study. Journal of Infection and Public Health, 10(5): 527-533.

Burke E (2015). Ten-Year Change in Blood Pressure Levels and Prevalence of Hypertension in Urban and Rural Cameroon. BMC Cardiovascular Disorders, 16(1): 1461-1473.

Chung-Delgado K, Guillen-Bravo S, RevillaMontag A, Bernabe-Ortiz A (2015). Mortality Among MDR-TB Cases: Comparison with Drug-Susceptible Tuberculosis and Associated Factors. PLoS ONE, 10(3): 1-10.

Craig GM, Zumla A. (2015). The Social Context of Tuberculosis Treatment in Urban Risk Groups in The United Kingdom: A Qualitative Interview Study. International Journal of Infectious Diseases, 32: 105-110.

Deshmukh RD, Dhande DJ, Sachdeva KS, Sreenivas A, Kumar AMV, Satyanarayana S, Parmar M et al. (2015). Patient and Provider Reported Reasons for Lost to Follow Up in MDRTB Treatment: A Qualitative Study from A Drug Resistant TB Centre in India. PLoS ONE, 10(8): 1-12.

Diefenbach-Elstob T, Plummer D, Dowi R, Wamagi S, Gula B, Siwaeya K, Pelowa Det al. (2017). The Social Determinants of Tuberculosis Treatment Adherence in A Remote Region of Papua New Guinea. BMC Public Health, 17(70): 1-12.

Ding P, Li X, Jia Z, Lu Z (2017). MultidrugResistant Tuberculosis (MDR-TB) Disease Burden in China: A Systematic Review and Spatio-Temporal Analysis. BMC Infectious Diseases, 17(57): 1-30.

Eastment MC, McClintock AH, McKinney CM, Narita M, Molnar A (2017). Factors That Influence Treatment Com- pletion for Latent Tuberculosis Infection. The Journal of the American Board of Family Medicine, 30(4): 520-527.

Fagundez G, Perez-Freixo H, EyeneJ, Momo JC, Biyé L, Esono T, Ayecab MOM et al. (2016). Treatment Adherence of Tuberculosis Patients Attending Two Reference Units in Equatorial Guinea.PLoS ONE, 11(9): 1-13.

Gaete J, Araya R (2017). Individual and Contextual Factors Associated with Tobacco, Alcohol, and Cannabis Use Among Chilean Adolescents: A Multilevel Study. Journal of Adolescence, 56: 166-178.

Herrero MB, Ramos S, Arrossi S (2015). Determinants of Non Adherence to Tuberculosis Treatment in Argentina: Barriers Related to Access to Treatment. Revista Brasileira de Epidemiologia, 18(2): 287-298.

Hicks RM, Padayatchi N, Shah NS, Wolf A, Werner L, Sunkari VB, O’Donnell MR (2014). Malnutrition Associated with Unfavorable Outcome and Death Among South African MDR-TB and HIV Co-Infected Children. International Journal of Tuberculosis and Lung Disease, 18(9): 1074-1079.

Hirpa S, Medhin G, Girma B, Melese M, Mekonen A, Suarez P and Ameni G. (2013). Determinants of MultidrugResistant Tuberculosis in Patients who Underwent First-Line Treatment in Addis Ababa: A Case Control Study. BMC Public Health, 13(782): 1-9.

Hoorn R, Jaramillo E, Collins D, Gebhard $A$, van den Hof $S$ (2016). The Effects of Psycho-Emotional and SocioEconomic Support for Tuberculosis Patients on Treatment Adherence and Treatment Outcomes - A Systematic Review and Meta-Analysis. PLoS ONE, 11(4): 1-27. 
Horne R, Chapman SCE, Parham R, Freemantle N, Forbes A, Cooper V (2013). Understanding Patients' AdherenceRelated Beliefs about Medicines Prescribed for Long-Term Conditions: A Meta-Analytic Review of The Necessity-Concerns Framework.PLoS ONE, 8(12): 1-24.

Hoza AS, Mfinanga SGM and König B. (2015). Anti-TB Drug Resistance in Tanga, Tanzania: A Cross Sectional Facility-Base Prevalence Among Pulmonary TB Patients. Asian Pacific Journal of Tropical Medicine, 8(11): 907-913.

Huong LTT, Long TK, Van Anh TT, TuyetHanh TT, Giang KB, Hai PT, Huyen DT et al. (2017). Exposure to Tobacco Advertising, Promotion Among the Adult Population in Vietnam and Its Implications for Public Health.Asia Pacific Journal of Public Health, 29(7): 569-579.

Jawad M, McIver C, Iqbal Z (2014). Prevalence and Correlates of Lifetime Waterpipe, Cigarette, Alcohol and Drug Use Among Secondary School Students in Stoke-on-Trent, UK: A Post Hoc Cross-Sectional Analysis. Journal of Public Health (Oxford, England), 36(4): 615-621.

Johari M, Eslami AA, Alahverdipoor H, Hasanzade A, Farid F (2014). Factors Related to Adopting Healthy Behaviors by Patients with Tuberculosis in Isfahan: Application of Health Belief Model. Journal of Education and Health Promotion, 3: 1-5.

Kementerian Kesehatan RI (2016) Profil Kesehatan Indonesia 2015. Jakarta: Kementerian Kesehatan RI.

Khan MS, Hutchison C, Coker RJ (2017). Risk Factors That May be Driving The Emergence of Drug Resistance in Tuberculosis Patients Treated in
Yangon, Myanmar. PLoS ONE, 12(6): 1-10.

Khanal S, Elsey H, King R, Baral SC, Bhatta BR, Newell JN (2017). Development of A Patient-Centred, Psychosocial Support Intervention for Multi-DrugResistant Tuberculosis (MDR-TB) Care in Nepal.PLoS ONE, 12(1): 1-16.

Kuchukhidze G, Kumar AMV, Colombani P de, Khogali M, Nanava U, Blumberg HM and Kempker RR. (2014). Risk Factors Associated with Loss to Follow-Up Among Multidrug-Resistant Tuberculosis Patients in Georgia. Public Health Action, 4(2): 247-252.

Ma E, Ren L, Wang W, Takahashi H, Wagatsuma Y, Ren Y, Gao Fet al. (2015). Demographic and Socioeconomic Disparity in Knowledge About Tuberculosis in Inner Mongolia, China. Journal of Epidemiology, 25(4): 312-320.

Molalign S, Wencheko E (2015). Risk Factors of Mortality in Patients with Multi-Drug Resistant TB. Ethiopia Health Journal, 29(2): 82-88.

Mollel EW, Chilongola JO (2017). Predictors for Mortality Among Multidrug-Resistant Tuberculosis Patients in Tanzania. Journal of Tropical Medicine, 1-6.

Muhammed S, Nagla S, Morten S, Asma E, Arja A (2015). Illness Perceptions and Quality of Life Among Tuberculosis Patients in Gezira, Sudan. African Health Sciences, 15(2): 385-393.

Ndwiga JM, Kikuvi G, Omolo JO (2016). Factors Influencing Knowledge on Completion of Treatment Among TB Patients Under Directly Observed Treatment Strategy, in Selected Health Facilities in Embu Country, Kenya. Pan African Medical Journal, 22(234): 1-8.

Park HO, Kim SH, Moon SH, Byun JH, Kim 
JW, Lee CE, Kim JDet al. (2016). Association between Body Mass Index and Sputum Culture Conversion Among South Korean Patients with Multidrug Resistant Tuberculosis in a Tuberculosis Referral Hospital. Infection and Chemotherapy, 48(4): 317323 .

Pärna K, Pürjer ML, Ringmets I and Tekkel M. (2014). Educational Differences in Cigarette Smoking Among Adult Population in Estonia, 1990-2010: Does The Trend Fit The Model of Tobacco Epidemic?.BMC Public Health, 14(709): 1-8.

Patel AR, Campbell JR, Sadatsafavi M, Marra F, Johnston JC, Smillie K, Lester RT (2017). Burden of NonAdherence to Latent Tuberculosis Infection Drug Therapy and The Potential Cost-Effectiveness of Adherence Interventions in Canada: A Simulation Study. BMJ Open, 7(9): 110.

Pedro JM, Brito M, Barros H (2017). Tobacco Consumption and Nicotine Dependence in Bengo Province, Angola: A Community-Based Survey. PLoS ONE, 12(11): 1-10.

Putri FA, Burhan E, Nawas A, Soepandi PZ, Sutoyo DK, Agustin H, Isbaniah F (2014) Body Mass Index Predictive of Sputum Culture Conversion Among MDR-TB Patients in Indonesia. International Journal of Tuberculosis and Lung Disease, 18(5): 564-570.

Rosenstock IM, Strecher VJ, Becker MH (1988). Social Learning Theory and The Health Belief Model.Health Education Quarterly, 15(2): 175-183.

Sanchez-Padilla E, Marquer C, Kalon S, Qayyum S, Hayrapetyan A, Varaine F, Bastard Met al. (2014). Reasons for Defaulting from Drug-Resistant Tuberculosis Treatment in Armenia:
A Quantitative and Qualitative Study. International Journal of Tuberculosis and Lung Disease, 18(2): 160-167.

Shringarpure KS, Isaakidis P, Sagili KD, Baxi RK, Das M, Daftary A (2016). When Treatment Is More Challenging Than The Disease: A Qualitative Study of MDR-TB Patient Retention. PLoS ONE, 11(3): 1-12.

Silva RD, de Luna FDT, de Araujo AJ, Camelo ELS, Bertolozzi MR, Hino P, Lacerda SNBet al. (2017). Patients' Perception Regarding The Influence of Individual and Social Vulnerabilities on The Adherence to Tuberculosis Treatment: A Qualitative Study. BMC public health, 17(725): 1-9.

Simpson V (2015). Models and Theories to Support Health Behavior Intervention and Program Planning. Health and Human Sciences, 1-5.

Skrahina A, Hurevich H, Zalutskaya A, Sahalchyk E, Astrauko A, Hoffner S, Rusovich V et al. (2013). MultidrugResistant Tuberculosis in Belarus: The Size of The Problem and Associated Risk Factors.Bulletin of the World Health Organization, 91(1): 3645 .

Tang S, Tan S, Yao L, Li F, Li L, Guo X, Liu $Y$ et al. (2013). Risk Factors for Poor Treatment Outcomes in Patients with MDR-TB and XDR-TB in China: Retrospective Multi-Center Investigation. PLoS ONE, 8(12): 1-9.

Tang Y, Zhao M, Wang Y, Gong Y, Yin X, Zhao A, Zheng J et al. (2015). NonAdherence to Anti-Tuberculosis Treatment Among Internal Migrants with Pulmonary Tuberculosis in Shenzhen, China: A Cross-Sectional Study.BMC Public Health, 15(474): 16.

Tola HH, Shojaeizadeh D, Tol A, Garmaroudi G, Yekaninejad MS, Kebede A, 
Journal of Epidemiology and Public Health (2017), 2(3): 241-254

https://doi.org/10.26911/jepublichealth.2017.02.03.06

Ejeta LT et al. (2016). Psychological and Educational Intervention to Improve Tuberculosis Treatment Adherence in Ethiopia Based on Health Belief Model: A Cluster Randomized Control Trial.PLoS ONE, 11(5): 1-15.

Tupasi T, Garfin AMCG, Mangan JM, Orillaza-Chi R, Naval LC, Balane GI, Basilio Ret al. (2017). MultidrugResistant Tuberculosis Patients' Views of Interventions to Reduce Treatment Loss to Follow-Up.The International Journal of Tuberculosis and Lung Disease, 21(1): 23-31.

Viegas AM, Miranda SS, João Paulo Haddad M, Ceccato, Carvalho W. (2017). Association of Outcomes with Comprehension, Adherence and Behavioral Characteristics of Tuberculosis Patients Using Fixed-Dose Combination Therapy In Contagem, Minas Gerais, Brazil.Journal of The Sao Paulo Institute of Tropical Medicine, 59(28): 1-6.

WHO (2013). Guideline: Nutritional Care and Support for Patients with Tuberculosis.

(2014). Global Tuberculosis Report 2014. Switzerland: WHO Press. (2015).Implementing the End TB Strategy: The Essentials, World Health Organization. (2016a).On The Road to Ending TB: Highlights from The 30 Highest TB Burden Countries. (2016b).WHO Global TB Report
2016 With HIV + TB, World Health Organisation (WHO) Report.

Woimo TT, Yimer WK, Bati T, Gesesew HA (2017). The Prevalence and Factors Associated for Anti-Tuberculosis Treatment Non-Adherence Among Pulmonary Tuberculosis Patients in Public Health Care Facilities in South Ethiopia: A Cross-Sectional Study. BMC Public Health, 17(269): 1-10.

Yaya S, Ghose B, Vaibhav S and Michael E (2017). Socioeconomic Disparities in Smoking Behavior and Early Smoking Initiation Among Men in Malawi. Tobacco Use Insights, 10: 1-7.

Zhang C, Wang Y, Shi G, Han W, Zhao H, Zhang H, Xi X (2016). Determinants of Multidrug-Resistant Tuberculosis in Henan Province in China: A Case Control Study. BMC Public Health, 16(42): 1-9.

Zhang H, Xin H, Li X, Li H, Li M, Lu W, Bai $L$ et al. (2017). A Dose-Response Relationship of Smoking with Tuberculosis Infection: A Cross-Sectional Study Among 21008 Rural Residents in China.PLoS ONE, 12(4): 1-14.

Zhang Q, Wu Z, Zhang Z, Sha W, Shen X, Xiao H (2015). Efficacy and Effect of Free Treatment on Multidrug Resistant Tuberculosis.Experimental and Therapeutic Medicine, 11(3): 777-782.

Zhdanov V, Bilenko N, Mor Z. (2017). Risk Factors for Recurrent Tuberculosis Among Successfully Treated Patients in Israel, 1999-2011. Israel Medical Association Journal, 19(4): 237-241. 